\title{
INTERPLAY OF THE DRIVERS AND DETERRENTS OF LEISURE COUNTERFEIT PURCHASE INTENTIONS
}

\author{
Mateja KOS KOKLIC ${ }^{1}$, Irena VIDA ${ }^{2}$ \\ Faculty of Economics, University of Ljubljana, Kardeljeva ploscad 17, \\ 1000 Ljubljana, Slovenia \\ E-mails: ${ }^{1}$ mateja.kos@ef.uni-lj.si (corresponding author); ${ }^{2}$ irena.vida@ef.uni-lj.si \\ Received 11 April 2014; accepted 30 November 2014
}

\begin{abstract}
Drawing on complementary theoretical perspectives, in this study we empirically investigate the drivers and deterrents underlying the formation of attitudes to leisure counterfeits and purchase intentions, and examine rationalization as a moderator of the attitude-intention relationship. The research model is examined via mail survey data of adult consumers using structural equations modelling. The findings indicate that perceived benefits and moral intensity significantly influence attitudes, while the impact of performance risk is negligible. The attitude and moral intensity significantly predict the purchase intention. Our analyses confirm rationalization as a salient factor moderating the relationship between attitude and behavioral intention. Based on this pattern of results, we discuss study implications in three areas: the perception of positive consequences for oneself, the perception of consequences for others, and the use of previously rarely examined consumer justifications. The finding that performance risk is not significant in affecting consumer attitude calls into question various appeals featuring adverse effects of buying counterfeits for an individual.
\end{abstract}

Keywords: counterfeits, perceived risk, perceived benefits, moral intensity, rationalization, purchase intention.

JEL Classification: M30, M31.

\section{Introduction}

The pervasive growth of counterfeit and pirated products represents a serious challenge to both companies in various industries and their stakeholders, including consumers. While estimates and statistics on the extent of the problem are particularly challenging in these elicit global markets, counterfeiting is believed to account for approximately $7 \%$ of all world trade, amounting to USD 600 billion (IAC 2012). Taking into account a projected growth rate of just under 15\%, the BASCAP industry report (2011) estimates the global value of international trade in the counterfeit and pirated product category to exceed USD 1 trillion by 2015. The counterfeiting of physical leisure goods is especially rampant, with apparel being the most popular counterfeited class of goods. 
Considering the extent of its global impact upon various stakeholders, the counterfeiting phenomenon has been of particular interest to consumer researchers. Since consumer demand creates the main market driver for the manufacture and sale of counterfeit products (Bian, Moutinho 2009), it is not surprising that research efforts in the past decades have yielded a large body of literature illuminating the demand side of both counterfeiting and piracy. However, the current research also identifies several unresolved research issues, some of which we attempt to address in this research.

The goal of this study is to examine both the drivers and deterrents of leisure counterfeit purchase intentions in the context of the adult population in a European Union country by drawing on complementary theoretical perspectives in the development of our conceptual model. In this model, we empirically explore: (a) two types of deterrents, i.e., performance risk (adverse impact on an individual) and moral intensity (perceived adverse impact on others); and (b) three drivers of the intention to buy a leisure counterfeit, i.e., perceived benefits (for an individual), positive attitudes and rationalization. Considering the dearth of studies offering insights into the role of justifications in the counterfeiting context (Kim et al. 2009; McGregor 2008), we further investigate how rationalizations tie into the mechanism of translating consumer attitudes into future purchase intentions.

In this study we focus on the volitional purchase of non-deceptive counterfeits. We further limit our investigation to counterfeit versions of physical leisure goods (Rutter, Bryce 2008) (e.g., fashion products) based on the following grounds: (a) leisure products constitute the majority of counterfeits seized at the European borders (EU Commission 2012); (b) items in this category are not prohibitively expensive allowing for an examination of purchase motivations beyond purely economic reasons; (c) both counterfeit and legitimate items are widely available in EU markets.

This study attempts to address an additional void identified in the current counterfeiting literature, i.e., the external validity and generalizability of existing research. Particularly in the category of leisure counterfeits, young people alone provide a relatively narrow fragment of the population. For example, Cheung and Prendergast (2006) show that counterfeit clothing and accessories were purchased by a more generic group than counterfeit video compact discs (VCDs).

\section{Theoretical underpinnings and conceptual framework for the study}

A state-of-the-art review of the current literature in both counterfeiting and piracy reveals that two theoretical approaches to the study of illicit purchase behavior stand out in particular: models of attitude-behavior relations, and theories of ethical decision making. For example, within the attitude-behavior relations domain, researchers previously built on two dominant theories, the Theory of Reasoned Action (e.g., Phau, Ng 2010) and the Theory of Planned Behavior (e.g., Chiu et al. 2014; de Matos et al. 2007). Further, theories of ethical decision making such as Hunt and Vitell's Theory (e.g., Shang et al. 2008) have also been applied when studying counterfeiting phenomena. 
Although identified as one of the most commonly used frameworks to study counterfeiting and piracy, the models of attitude-behavior relations have been criticized because attitudes alone are poor predictors of behaviors (e.g., De Pelsmacker, Janssens 2007). Since counterfeiting is, depending on the situation, considered an illegal practice (INTA 2014), the decision to purchase counterfeit products involves stimuli that may evoke certain ethical dilemmas. In this respect, the ethical research stream offers an insightful basis for identifying potentially relevant factors underlying counterfeit behavior. For example, to recognize the importance of examining the effect of moral perceptions, Jones (1991) proposed the issue-contingent model which holds that ethical decisions are primarily contingent upon the characteristics of the moral issue as captured in the concept of moral intensity. Another promising, yet relatively unexplored area relates to the expected outcomes of that behavior. An individual's choice of behavior is strongly based on the probability that a certain action will provoke a specific negative or positive consequence (Limayem et al. 2004).

Both theoretical approaches, the attitude-behavior models and ethical decision making, are established on the fundamental premise that in most cases individuals' intentions are consistent with their underlying attitudes (Chatzidakis et al. 2007). However, as several studies indicate, oftentimes consumer attitudes are not translated into subsequent congruent purchase intentions and behavior (e.g., Chatzidakis et al. 2007). This discrepancy has been addressed by the neutralization theory that explains how individuals attenuate the feeling of guilt and shame that may inhibit their non-normative behavior (Siponen et al. 2012). Namely, the underlying assumption for the neutralization need to arise is that behavior violates social norms or that social norms are not internalized to the degree that they guide behavior in all circumstances (Chatzidakis et al. 2007). Using neutralization strategies helps consumers to reconcile the discrepancies between such behavior and the positive self-image they wish to project (Cheng et al. 2014). Coined by Sykes and Matza (1957), neutralization theory suggests that individuals learn a set of justifications or rationalizations, i.e., neutralization techniques. Originally, five techniques of neutralization were explicated in their work: denial of responsibility (one places the blame on other factors), denial of injury (one sees no particular harm by the behavior), denial of victim (one believes it it the victim's fault), condemnation of the condemners (one points at those who disapprove of his behavior), and appeal to higher loyalties (one supports a cause or entity outside of and above oneself) (Chatzidakis et al. 2007; Hinduja 2007; Sykes, Matza 1957).

Against this theoretical background, we develop a conceptual framework of the interplay of the drivers and deterrents of leisure counterfeit (LCF) purchase intention depicted in Figure 1. In this model, perceived performance risk, perceived benefits and moral intensity are modeled as exogenous variables, while a favorable attitude to purchasing LCF is modeled as a mediator between exogenous variables and future purchase intention. Moreover, we posit that rationalization plays a moderating role in the relationship between favorable attitude and LCF purchase intention. The three exogenous variables in the model reflect drivers and deterrents with respect to the perceived expected consequences of a counterfeit purchase. Performance risk assesses the 


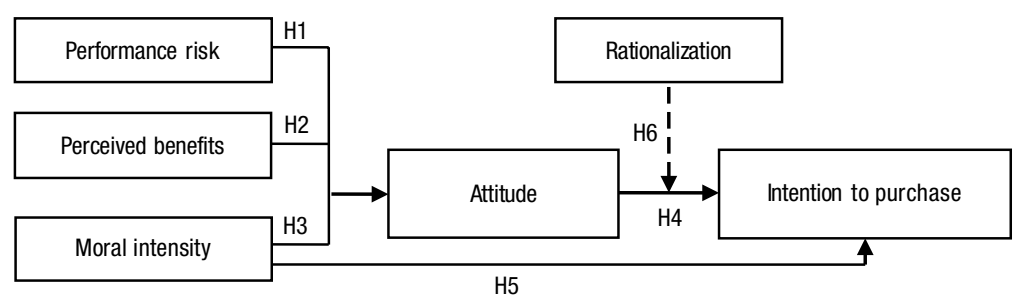

Fig. 1. Conceptual framework

negative consequences for the individual purchasing counterfeit products in terms of the adequacy of LCF products. An individual's perception of positive consequences of purchasing an LCF product is mirrored in perceived benefits. By drawing on the ethical decision-making theories, we include moral intensity as a deterrent of LCF in that it reflects an individual's expected adverse effects of counterfeiting for others and society at large (Kos Koklic et al. 2014). We posit moral intensity affects both the attitude to LCF and LCF purchase intention. Consistent with the theoretical grounding discussed earlier, attitude is conceptualized as a learned predisposition to respond in a consistently favorable manner with respect to purchasing LCF, while the intention to buy counterfeits refers to the likelihood that consumers will purchase LCF products in the future. Lastly, in positing a moderating effect of rationalization, we define the concept as a consumer's technique to counter the feelings of guilt associated with their past engagement in purchasing counterfeits by using a set of justifications (Kim et al. 2012).

\section{Hypotheses development}

\subsection{Drivers and deterrents of the attitude to purchasing leisure counterfeits}

The first set of hypotheses $(\mathrm{H} 1, \mathrm{H} 2$, and H3) refers to the determinants of a person's attitude toward purchasing LCF. Several studies offer evidence that a perceived risk diminishes a consumer's favorable attitude to buying a counterfeit product. In the context of purchasing counterfeits various risk dimensions were attested. For example, Chiou et al. (2005) found that perceived prosecution risk negatively affects consumers' general attitudes to counterfeit music CD purchases. Similarly, de Matos et al. (2007) confirm the negative impact of perceived performance and monetary risk on the attitude to counterfeits. High level of performance risk in case of buying counterfeit sunglasses was also demonstrated in Veloutsou and Bian's study (2008).

Next, we examine the role of perceived benefits as drivers of a consumer's attitude to buying counterfeit products. While many counterfeiting studies investigate specific benefits as direct determinants of purchase intent or behavior, few empirical studies examine perceived benefits as shaping attitudes to counterfeiting. For example, Yoon (2011) shows that benefits as perceived consequences of intended action have a significant impact on attitudes to digital piracy.

Given the scarcity of studies in the counterfeiting context which include moral intensity, we rely on evidence from the general business and piracy research and ethics-related 
constructs applied in previous research. For example, Chiou et al. (2005) demonstrate that moral intensity negatively affects attitudes to buying unauthorized music downloads/duplication. As attitude is the closest construct to individuals' moral judgment (Al-Rafee, Cronan 2006), another line of evidence is provided by Morris and McDonald (1995) who found that moral intensity significantly affects moral judgment. Hence, we postulate:

H1: Perceived performance risk negatively affects the attitude to purchasing LCF products.

H2: Perceived benefits positively affect the attitude to purchasing LCF products.

H3: Moral intensity negatively affects the attitude to purchasing LCF products.

\subsection{Drivers and deterrents of the intention to purchase leisure counterfeits}

The next set of hypotheses (H4, H5) focuses on the determinants of an individual's intent to purchase a counterfeit product. There is a bulk of evidence in favor of a significant relationship between attitudes and behavioral intentions in the counterfeiting context. For example, Chiou et al. (2005) explore this link in the context of purchasing counterfeit CDs and Chiu et al. (2014) provide evidence for this relationship in case of counterfeit sporting goods.

As postulated by Jones (1991), an important determinant of behavioral intention is moral intensity because the decision-making process involved in engaging in an illicit act will be impacted by the specific moral dilemma at hand. Several studies in the piracy context indicate that moral intensity diminishes a person's intent to obtain pirated products (e.g., Chen et al. 2009; Tan 2002). On the other hand, Kim et al. (2009) found no empirical support for a negative effect of moral intensity on a person's intention to purchase counterfeits. We propose testing the following hypotheses:

H4: Favorable attitude to purchasing LCF products positively affects the intention to purchase LCF products.

H5: Moral intensity negatively affects the intention to purchase LCF products.

\subsection{The moderating role of rationalization}

Rationalization (or neutralization) as a technique individuals apply when making decisions to engage in behavior they know to be wrong (Sykes, Matza 1957) has frequently been a subject of interest in digital piracy studies (e.g., Phau, Ng 2010). In the counterfeiting literature, rationalization (or justification) has seldom been addressed (e.g., Carpenter, Lear 2011). Chatzidakis et al. (2007) proposed examining the rationalization construct as a complement to the existing models of ethical decision making, and suggest that individuals apply rationalization between attitude and intent. Although rare, some empirical evidence for the role of rationalization as a moderator of the relationship between attitude and behavioral intention can be found in other research settings, e.g., ethical decision making (Yang 2008). We thus hypothesize:

H6: The stronger the rationalization, the stronger the relationship between the attitude to purchasing LCF products and the intention to purchase LCF products. 


\section{Methodology}

\subsection{Sample and procedure}

The conceptual model proposed in Figure 1 was investigated on a sample of 584 consumers in a Central European country within a framework of a wider EU investigation of economics and social impacts of counterfeiting in 2010. A self-administered nationwide survey was sent to an initial randomly selected sample of 10,000 adult consumers, which was obtained from the National Statistical Office and was representative of the adult population in terms of gender, age, type of settlement and region of the country. Only those respondents who had actually purchased at least one LCF product (clothes and other fashion items, DVDs, CDs, software, books) in their lifetime were asked to respond to our questions. In order to test for nonresponse bias, we compared early and late respondents and found no significant differences in the mean responses to key constructs between these two groups of respondents.

Overall, our sample of 584 individuals consisted of more female $(53.8 \%)$ than male respondents with an average age of 40.3 years. The majority of the respondents $(76.8 \%)$ had attained a college education, and almost half of the sample (49.9\%) was employed on either a part-time or full-time basis. In our sample, 27.9 percent reported having purchased counterfeit clothes and/or other fashion accessory items (e.g., bags, sunglasses) in the past six months, 11.3 percent counterfeit music tracks, $7.4 \%$ counterfeit films/TV shows, followed by the purchase of counterfeit application software, games software and books/magazines (with 6.7, 4.8 and 5.0\%, respectively). This is consistent with our definition of LCF products.

\subsection{Instrument development}

The construct measures were based on the existing literature but carefully adapted to the cultural context with an additional testing for reliability (De Jong et al. 2009). Five constructs identified in the conceptual model were measured on 5-point Likert-type scales $(1=$ Strongly Disagree; $5=$ Strongly Agree $)$, and moral intensity on a 5-point semantic differential scale.

The performance risk measure was adapted from the Hennig-Thurau, Henning, and Sattler (2007) scale, and consisted of items pertaining to overall quality, durability and safety. Measures for perceived benefits were also derived from the Hennig-Thurau et al. (2007) scale and tapped into the performance, appearance and image of LCFs. Moral intensity was operationalized in line with Jones's (1991) components, where we adapted the four-item scale from McMahon and Harvey (2006). To capture the attitude to purchasing LCFs, items were adapted from the de Matos et al. (2007) study. The counterfeit purchase intention was assessed using the scale developed by Taylor and Todd (1995). The rationalization scale was devised based on the techniques of neutralization identified by Sykes and Matza (1957). 


\section{Analyses and results}

\subsection{Measurement model}

The analysis uses structural equation modeling and was conducted in two steps. After an exploratory factor analysis, the measures were submitted to a confirmatory factor analysis. To assess the reliability of the constructs, three test indices were used: Cronbach's alpha, composite reliability and average variance extracted (Table 1). First, internal consistency was assessed by calculating alpha for each construct. All the values exceed .60 ranging from 0.78 to 0.84 . The scales also exhibited acceptable composite reliability (CR) and average variance extracted (AVE), with the former ranging from 0.790 to 0.845 and the latter varying from 0.556 to 0.732 , with cut-off values of 0.70 and 0.50 , respectively.

Table 1. Measurement model properties

\begin{tabular}{|c|c|c|c|}
\hline Construct & $\begin{array}{l}\text { Std. factor } \\
\text { loadings }\end{array}$ & $\mathrm{CR}$ & AVE \\
\hline $\begin{array}{l}\text { Performance risk ( } \alpha=0.81) \\
\text { Buying counterfeit goods is risky because.... }\end{array}$ & & 0.824 & 0.615 \\
\hline 1. ...they are generally of poor quality. & 0.855 & & \\
\hline 2. ...they are not as durable as the real products. & 0.871 & & \\
\hline 3. ...they might not be safe. & 0.595 & & \\
\hline Perceived benefits $(\alpha=0.78)$ & & 0.790 & 0.556 \\
\hline 1. Counterfeit goods do the same thing as the legal products. & 0.679 & & \\
\hline 2. Counterfeit goods look the same as legal ones. & 0.795 & & \\
\hline 3. Counterfeit goods provide the same image as legal ones. & 0.760 & & \\
\hline $\begin{array}{l}\text { Moral intensity ( } \alpha=0.82) \\
\text { If you bought counterfeit goods: }\end{array}$ & & 0.840 & 0.580 \\
\hline $\begin{array}{l}\text { 1. What kind of impact do you think it would have on society? } \\
(1 \text { - Very Positive to } 5 \text { - Very Negative) }\end{array}$ & 0.626 & & \\
\hline $\begin{array}{l}\text { 2. What would the size of this impact be? } \\
(1-\text { Very Small to } 5 \text { - Very Large) }\end{array}$ & 0.934 & & \\
\hline $\begin{array}{l}\text { 3. How likely is it that this impact would be felt? } \\
\text { ( } 1 \text { - Highly Unlikely to } 5 \text { - Highly Likely) }\end{array}$ & 0.874 & & \\
\hline $\begin{array}{l}\text { 4. What would the nature of this impact be? } \\
(1-\text { Very Short Term to } 5 \text { - Very Long Term) }\end{array}$ & 0.539 & & \\
\hline Attitude $(\alpha=0.83)$ & & 0.837 & 0.633 \\
\hline 1. I would enjoy buying counterfeit goods. & 0.732 & & \\
\hline 2. Buying counterfeit goods would make me feel satisfied. & 0.853 & & \\
\hline 3. Buying counterfeit goods would make me feel happy. & 0.793 & & \\
\hline
\end{tabular}


End of Table 1

\begin{tabular}{lccc}
\hline \multicolumn{1}{c}{ Construct } & $\begin{array}{c}\text { Std. factor } \\
\text { loadings }\end{array}$ & CR & AVE \\
\hline Intention to purchase $(\alpha=0.84)$ & $0.845 \quad$ & 0.732 \\
\hline 1. I intend to buy counterfeit goods in the future. & 0.887 & \\
\hline 2. If the need or opportunity arises within the next six months, & 0.822 & \\
I would buy counterfeit goods. & & \\
\hline \hline Neutralization $(\alpha=0.73)$ & & \\
\hline 1. I couldn't help myself; I had to buy them. & \\
\hline 2. It's no big deal as no one was hurt. & \\
\hline 3. I was only doing what others do all the time. & \\
\hline
\end{tabular}

Following the established procedure by Anderson and Gerbing (1988) we also checked discriminant validity which proved to be acceptable. All factor loadings and error variances were statistically significant at $\mathrm{p}>0.05$ which confirms the convergent validity of the indicators. Furthermore, the fit indexes of the measurement model indicate a good fit of the model to the data $\left(\chi^{2}=160.813\right.$, d.f. $=76, p=0.00$; GFI $=0.97$; AGFI $=0.95$; $\mathrm{RMR}=0.04 ; \mathrm{sRMR}=0.04$; RMSEA $=0.04)$. The final measurement model consisted of six latent constructs and 18 items.

\subsection{Structural model}

Next, the structural model was evaluated using t-statistics to test the hypothesized relationships between constructs. In addition, since we hypothesized that rationalization plays a moderating role, factor scores were created for the predictor (Attitude) and the moderator (Rationalization) using exploratory factor analysis. Then, the product of those factor scores was created and used as a single indicator in testing the structural model.

The model fit measures show that the data conform well to the model. The RMSEA (0.05) was well below the 0.08 cutoff values (Browne, Cudeck 1993). In addition, the GFI and AGFI (0.95 and 0.93, respectively) were both equal to or above the commonly recommended 0.90 limit. Finally, the RMR and standardized RMR (both 0.05) also provide evidence of a good fit.

T-statistics from the structural model were used to examine the hypotheses. As indicated in the summary of results in Table 2, the proposed relationships proved to be in the hypothesized direction and statistically significant, with the exception of the link between performance risk and attitude.

Additionally, we conducted a mediation test to better understand the role of Attitudes as a mediator (Baron, Kenny 1986). Thus, we ran a second structural model without the link corresponding to H4. The large chi-square difference indicates that the mediated model (corresponding to our conceptual model) is a much better fit with the data. The comparison of the results for H5 in the direct and the mediated model (see Table 2) indicates a partial mediation of Attitude on the Moral intensity-Intention link. 
Table 2. Hypotheses testing and results

\begin{tabular}{lccc}
\hline \multicolumn{1}{c}{ Causal path } & $\begin{array}{c}\text { Path coefficients } \\
\text { (t-value) in } \\
\text { mediated model }\end{array}$ & $\begin{array}{c}\text { Path coefficients } \\
\text { (t-value) in direct } \\
\text { model }\end{array}$ & $\begin{array}{c}\text { Hypothesis } \\
\text { supported }\end{array}$ \\
\hline H1- Performance risk $\rightarrow$ Attitude & $-0.04(-0.75)$ & $-0.04(-0.63)$ & No \\
\hline H2+ Perceived benefits $\rightarrow$ Attitude & $0.32 *(5.25)$ & $0.29 *(4.92)$ & Yes \\
\hline H3- Moral intensity $\rightarrow$ Attitude & $-0.15^{*}(-2.91)$ & $-0.16^{*}(-3.20)$ & Yes \\
\hline H4+ Attitude $\rightarrow$ Intention & $0.39^{*}(7.89)$ & - & Yes \\
\hline H5- Moral intensity $\rightarrow$ Intention & $-0.21^{*}(-4.57)$ & $-0.31(-6.21)$ & Yes \\
\hline H6+ Neutralization $\rightarrow$ Attitude-Intention & $0.09^{*}(2.32)$ & $0.09 *(2.12)$ & Yes \\
\hline
\end{tabular}

Note: * Significant at $\mathrm{p} \leq 0.05$ if $|\mathrm{t}| \geq 1.96$.

To further examine the effect of rationalization, we conducted moderated mediation defined as the magnitude of an indirect effect at a particular value of a moderator (Preacher et al. 2007). More specifically, we probed the magnitude of the conditional indirect effect across low and high levels of rationalization. Results show that the conditional indirect effect for moral intensity on purchase intention was significant in the high rationalization condition, but insignificant under the low rationalization condition. Since the conditional indirect effect of moral intensity on intention, via attitude, differs in strength, moderated mediation is demonstrated.

\section{Discussion of research findings}

All of the proposed hypotheses were supported with the exception of the effect of performance risk regarding the product adequacy of LCFs on consumer attitudes to purchasing LCFs. Next, we discuss these results in light of the existing body of knowledge on counterfeiting, first with respect to the deterrents and then the drivers of LCF purchase intentions.

Our analyses of the nationwide data confirm a strong role of moral intensity in LCF purchase intent in both: (a) driving the attitudes (H3); and (b) directly affecting leisure counterfeit purchase intentions (H5). The result pertaining to Hypothesis 3 demonstrates that consumers tend to shape their positive predispositions based on their perception of the adverse effects of counterfeiting on others and society at large (i.e., in terms of the valance, scope and temporal effects of the impact). While consistent with the quite scarce empirical evidence in the existing literature (e.g., Chiou et al. 2005; Morris, McDonald 1995), this is an important finding that advances knowledge of the role of moral intensity in shaping attitudes of the general population.

What is more, we found that moral intensity directly impacts consumer intention to purchase LCFs (H5), corroborating previous counterfeiting studies (e.g., Chen et al. 2009; Tan 2002). This means that when consumers contemplate the morality of their counterfeit purchases in terms of the adverse consequences for others, their intention to engage in purchasing counterfeits diminishes. 
In contrast, our results lend no empirical support to the hypothesis (H1) stating a negative impact of performance risk on the attitude to counterfeiting. While unexpected, this finding may be related to the scope of our risk measure which was limited to the product adequacy (performance) of LCFs. It is possible that other types of risk (e.g. social risk) more prominently shape a person's attitude to purchasing counterfeits. Alternatively, the performance risk dimension might have proven insignificant since counterfeit leisure goods as defined in our study comprise various product categories. Consumers might feel susceptible to different types of perceived risk when purchasing fake fashion items (e.g., social risk) vs. when purchasing fake DVDs (e.g., functional risk). Another plausible explanation pertains to the research context of LCFs that may require a fairly low involvement in the purchase situation, with the performance risk being less pronounced.

With respect to the drivers of LCF purchase intention, our analyses confirm the role of perceived benefits, attitude and rationalization. First, we find that an individual's expectations regarding LCFs relative to the genuine products positively shape the attitude to counterfeits (H2). Previous research suggests that providing the same looks and image relates to consumers' tendency to deceive others in order to signal positive traits and to socially position themselves (Wall, Large 2010). Second, in line with previous empirical work on mostly student samples, our results demonstrate the attitude to purchasing LCFs significantly affects the intention to purchase LCFs (H4). Hence, while criticized for being a poor predictor of behavior (e.g., De Pelsmacker, Janssens 2007), attitude seems to be one of the consistent predictors of behavioral intention irrespective of the research context.

Third, we find that rationalizing beliefs held by an individual significantly moderate the relationship between attitude and intention to purchase LCFs (H6). Specifically, the more consumers resort to rationalization techniques, the more likely a favorable attitude to buying LCFs translates into a future purchase intention. Moreover, this finding supports the theoretical proposition of Chatzidakis et al. (2007) on the moderating role of neutralization, and adds to the variety of contexts in which rationalization has been tested as a moderator (e.g., Yang 2008).

\section{Conclusions}

The findings of this study afford useful implications for marketers in various industries, particularly the fashion industry, movie and music industries. Researchers and practitioners generally agree that shaping the demand for counterfeits and consumer education constitute major tools for confining the counterfeiting phenomenon. Given that attitudes can be changed through persuasion and other means and intentions serve as relatively reliable predictors of future behavior, focusing on consumer attitudes and intentions in managing the demand for counterfeits seems to offer fertile grounds. One of the crucial findings of our study is that attitude to purchasing LCFs directly as well as indirectly impinges on the intention to purchase LCFs by mediating the impact of perceived benefits and moral intensity on the intention to purchase LCFs. Furthermore, the strength of the impact of moral intensity on the intention is contingent upon the level 
of consumer's rationalization. Our results reveal three important areas in understanding the attitude-intention dynamics: the perception of positive consequences for oneself (i.e., perceived benefits), the perception of consequences for others (i.e., moral intensity), and the use of justifications (i.e., rationalization). On the other hand, performance risk is not significant in affecting consumer attitude which calls into question various appeals featuring adverse effects of buying counterfeits for an individual - at least with respect to their quality, durability and safety.

Based on our findings, there are several ways to discourage consumers from purchasing LCFs. First, genuine item producers can benefit from widening the perceptual gap between the counterfeit and the original, and thus influence how consumers view the performance, appearance and image of counterfeits in comparison to genuine products. As the perceptual gap widens, consumers perceive fewer benefits from buying a counterfeit leisure product.

Second, our findings also reveal that consumer perceptions of consequences at the societal level (via moral intensity) play a significant role in driving both a favorable attitude and purchase intent. This means marketers could shape consumers' attitudes and consequently their intentions by emphasizing potentially harmful consequences for society, either in terms of valence (negative), size (large), likelihood (very likely felt) or duration (long-term). Alternatively, instead of emphasizing negative consequences for the society as in many existing anti-piracy campaigns, advertisements could promote positive consequences of not purchasing counterfeits which is believed to be more powerful.

Third, designing marketing communications with the use of rationalization might also prove valuable in deterring consumer willingness to purchase LCFs. Since the use of rationalization techniques is found to enhance the impact of attitudes on the intention to purchase LCFs, marketing communications and persuasion activities should explicitly counter the arguments that consumers typically employ to justify their behavior. Based on our analysis, three types of appeals might prove especially effective: countering consumer's contention that one is not responsible for their action, countering consumer's belief that there is no harm produced by their behavior, and countering consumer's belief that others perform this same behavior.

Despite the systematic approach in the design and the implementation of our empirical research, several limitations apply to this cross-sectional survey based study. Our measure of performance risk was limited to the functional/performance aspect, leaving out potential other aspects relevant to an individual's consideration of a LCF purchase, such as perceived social risk. Similarly, the scope of perceived benefits could capture a broader scope of benefits, including financial ones. Price represents an important advantage of a counterfeit over a genuine item that was unaccounted for in this study. Finally, in order to enhance the external validity of the model, a comparative study between major cultures and countries would be beneficial. Considering the continuing growth of counterfeiting and its global nature, such research would offer insights into the current strategies to curb this phenomenon which need to be adapted to the specific cultural context. 


\section{References}

Al-Rafee, S.; Cronan, T. P. 2006. Digital piracy: factors that influence attitude toward behavior, Journal of Business Ethics 63(3): 237-259. http://dx.doi.org/10.1007/s10551-005-1902-9

Anderson, J. C.; Gerbing, D. 1988. Structural equation modeling in practice: a review and recommended two-step approach, Psychological Bulletin 103(3): 411-423.

http://dx.doi.org/10.1037/0033-2909.103.3.411

BASCAP. 2011. Estimating the global economic and social impacts of counterfeiting and piracy [online], [cited 5 January 2014]. Business Action to Stop Counterfeiting and Piracy. Available from Internet: http://www.iccwbo.org/Advocacy-Codes-and-Rules/BASCAP/BASCAP-Research/ Economic-impact/Global-Impacts-Study/

Baron, R. M.; Kenny, D. A. 1986. The moderator-mediator variable distinction in social psychological research: conceptual, strategic, and statistical considerations, Journal of Personality and Social Psychology 51(6): 1173-1182. http://dx.doi.org/10.1037/0022-3514.51.6.1173

Bian, X.; Moutinho, L. 2009. An investigation of determinants of counterfeit purchase consideration, Journal of Business Research 62(3): 368-378.

http://dx.doi.org/10.1016/j.jbusres.2008.05.012

Browne, M. W.; Cudeck, R. 1993. Alternative ways in assessing model fit, in K. A. Bollen, J. S. Long (Eds.). Testing structural equations models. Beverly Hills, CA: Sage Publications.

Carpenter, J. M.; Lear, K. 2011. Consumer attitudes toward counterfeit fashion products: does gender matter?, Journal of Textile and Apparel, Technology and Management 7(1): 1-16.

Chatzidakis, A.; Hibbert, S.; Smith, A. P. 2007. Why people don't take their concerns about fair trade to the supermarket: the role of neutralization, Journal of Business Ethics 74(1): 89-100. http://dx.doi.org/10.1007/s10551-006-9222-2

Chen, M. F.; Pan, C. T.; Pan, M. C. 2009. The joint moderating impact of moral intensity and moral judgment on consumer's use intention of pirated software, Journal of Business Ethics 90(3): 361-373. http://dx.doi.org/10.1007/s10551-009-0046-8

Cheng, L.; Li, W.; Zhai, Q.; Smyth, R. 2014. Understanding personal use of the Internet at work: an integrated model of neutralization techniques and general deterrence theory, Computers in Human Behavior 38: 220-228. http://dx.doi.org/10.1016/j.chb.2014.05.043

Cheung, W.-L.; Prendergast, G. 2006. Buyers' perceptions of pirated products in China, Marketing Intelligence \& Planning 24(5): 446-462. http://dx.doi.org/10.1108/02634500610682854

Chiou, J.-S.; Huang, C.; Lee, H. 2005. The antecedents of music piracy attitudes and intentions, Journal of Business Ethics 57(2): 161-174. http://dx.doi.org/10.1007/s10551-004-5263-6

Chiu, W.; Lee, K.-Y.; Won, D. 2014. Consumer behavior toward counterfeit sporting goods, Social Behavior and Personality 42(2): 615-624. http://dx.doi.org/10.2224/sbp.2014.42.4.615

De Jong, M. G.; Steenkamp, J.-B. E. M.; Veldkamp, B. P. 2009. A model for the construction of country-specific, yet internationally comparable short-form marketing scales, Marketing Science 28(4): 674-689. http://dx.doi.org/10.1287/mksc.1080.0439

De Matos, C. A; Ituassu, C. T.; Rossi, C. A. V. 2007. Consumer attitudes toward counterfeits: a review and extension, Journal of Consumer Marketing 24(1): 36-47.

http://dx.doi.org/10.1108/07363760710720975

De Pelsmacker, P.; Janssens, W. 2007. A model for fair trade buying behaviour: the role of perceived quantity and quality of information and of product-specific attitudes, Journal of Business Ethics 75(4): 361-380. http://dx.doi.org/10.1007/s10551-006-9259-2

EU Commission. 2012. Report on EU customs enforcement of intellectual property rights [online], [cited 12 February 2014]. Available from Internet: http://ec.europa.eu/taxation_customs/ resources/documents/customs/customs_controls/counterfeit_piracy/statistics/2012__ipr_statistics_en.pdf 
Hennig-Thurau, T.; Henning V.; Sattler, H. 2007. Consumer file sharing of motion pictures, Journal of Marketing 71(4): 1-18. http://dx.doi.org/10.1509/jmkg.71.4.1

Hinduja, S. 2007. Neutralization theory and online software piracy: an empirical analysis, Ethics and Information Technology 9(3): 187-204. http://dx.doi.org/10.1007/s10676-007-9143-5

INTA. 2014. Counterfeiting [online], [cited 07 August 2014]. International Trade Association. Available from Internet: http://www.inta.org/TrademarkBasics/FactSheets/Pages/Counterfeiting. aspx

IAC. 2012. About counterfeiting [online], [cited 12 February 2014]. International Anticounterfeiting Coalition. Available from Internet: http://www.iacc.org/about-counterfeiting/

Jones, T. M. 1991. Ethical decision making by individuals in organizations: an issue-contingent model, Academy of Management Review 16(2): 366-395.

Kim, J.-E.; Cho, H. J.; Johnson, K. 2009. Influence of moral affect, judgment, and intensity on decision making concerning counterfeit, gray-market, and imitation products, Clothing and Textiles Research Journal 27(3): 211-226. http://dx.doi.org/10.1177/0887302X08327993

Kim, J.; Kim, J.-E.; Park, J. 2012. Effect of cognitive resource availability on consumer decisions involving counterfeit products: the role of perceived justification, Marketing Letters 23: 869-881. http://dx.doi.org/10.1007/s11002-012-9194-1

Kos Koklic, M.; Vida, I.; Bajde, D.; Culiberg, B. 2014. The study of perceived adverse effects of digital piracy and involvement: insights from adult computer users, Behaviour \& Information Technology 33(3): 225-236. http://dx.doi.org/10.1080/0144929X.2012.753552

Limayem, M.; Khalifa, M.; Chin, W. W. 2004. Factors motivating software piracy: a longitudinal study, IEEE Transactions on Engineering Management 51: 414-425.

http://dx.doi.org/10.1109/TEM.2004.835087

McGregor, S. L. T. 2008. Conceptualizing immoral and unethical consumption using neutralization theory, Family and Consumer Sciences Research Journal 36(3): 261-276.

http://dx.doi.org/10.1177/1077727X07312190

McMahon, J. M.; Harvey, R. J. 2006. An analysis of the factor structure of Jones' moral. Intensity construct, Journal of Business Ethics 64(4): 381-404.

http://dx.doi.org/10.1007/s10551-006-0006-5

Moon, S. I.; Kim, K.; Feeley, T. H.; Shin, D. H. 2014. A normative approach to reducing illegal music downloading: the persuasive effects of normative message framing, Telematics and Informatics 32(1): 169-179. http://dx.doi.org/10.1016/j.tele.2014.06.003

Morris, S. A.; McDonald, R. A. 1995. The role of moral intensity in moral judgments: an empirical investigation, Journal of Business Ethics 14(9): 715-726.

http://dx.doi.org/10.1007/BF00872325

Phau, I.; Ng, J. 2010. Predictors of usage intentions of pirated software, Journal of Business Ethics 94(1): 23-37. http://dx.doi.org/10.1007/s10551-009-0247-1

Preacher, K. J.; Rucker, D. D.; Hayes, A. F. 2007. Addressing moderated mediation hypotheses: theory, methods, and prescriptions, Multivariate Behavioral Research 42(1): 185-227.

http://dx.doi.org/10.1080/00273170701341316

Rutter, J.; Bryce, J. 2008. The consumption of counterfeit goods: "Here be pirates"?, Sociology 42(6): 1146-1164. http://dx.doi.org/10.1177/0038038508096938

Shang, R.-A.; Chen, Y.-C.; Chen, P.-C. 2008. Ethical decisions about sharing music files in the P2P environment, Journal of Business Ethics 80(2): 349-365.

http://dx.doi.org/10.1007/s10551-007-9424-2

Siponen, M.; Vance, A.; Willison, R. 2012. New insights into the problem of software piracy: the effects of neutralization, shame, and moral beliefs, Information \& Management 49(7): 334-341. http://dx.doi.org/10.1016/j.im.2012.06.004 
Sykes, G.; Matza, D. 1957. Techniques of neutralization: a theory of delinquency, American Sociological Review 22(6): 664-670. http://dx.doi.org/10.2307/2089195

Tan, B. 2002. Understanding consumer ethical decision making with respect to purchase of pirated software, Journal of Consumer Marketing 19(2): 96-111.

http://dx.doi.org/10.1108/07363760210420531

Taylor, S.; Todd, P. 1995. Assessing IT usage: the role of prior experience, MIS Quarterly 19(4): 561-570. http://dx.doi.org/10.2307/249633

Veloutsou, C.; Bian, X. 2008. A cross-national examination of consumer perceived risk in the context of non-deceptive counterfeit brands, Journal of Consumer Behaviour 7(1): 3-20.

http://dx.doi.org/10.1002/cb.231

Wall, D. S.; Large, J. 2010. Jailhouse frocks: locating the public interest in policing counterfeit luxury fashion goods, British Journal of Criminology 50(6): 1094-1116.

http://dx.doi.org/10.1093/bjc/azq048

Yang, S. T. 2008. The roles of anticipated guilt, neutralisation and advertising appeals in consumers' ethical decision-making: Master's thesis. University of Nottingham.

Yoon, C. 2011. Theory of planned behavior and ethics theory in digital piracy: an integrated model, Journal of Business Ethics 100(3): 405-417. http://dx.doi.org/10.1007/s10551-010-0687-7

Mateja KOS KOKLIC is an Assistant Professor of Marketing at the Faculty of Economics, University of Ljubljana, Slovenia. Her main research interests lie in the areas of consumer behaviour and consumer decision making, especially piracy and counterfeiting, as well as strategic household purchases. She has published in journals, such as Journal of Business Ethics, International Journal of Consumer Studies, and Behaviour \& Information Technology.

Irena VIDA is a Professor of Marketing at the Faculty of Economics, University of Ljubljana, Slovenia. Her research focus is on application of consumer behaviour theories and models in cross-cultural settings and on strategic issues in international marketing. She published articles in various journals such as Journal of Business Research, European Journal of Marketing, Journal of International Marketing, International Marketing Review, and International Business Review. 